\title{
Comercio electrónico en China y México: surgimiento, evolución y perspectivas
}

\section{Electronic Commerce in China and Mexico: Emergence, Evolution and Perspectives}

DOI: $10.32870 /$ mycp.v9i27.688

Juan González García ${ }^{1}$

\section{Resumen}

En este artículo se analiza el surgimiento en el mundo del comercio electrónico, haciendo hincapié en los casos de México y China, países que han implementado una serie de acciones, estrategias, programas e incluso planes para incentivar el uso de los medios electrónicos y digitales en las transacciones de los agentes económicos. Se encuentra que China se ha convertido en un país líder en el uso del comercio electrónico, gracias a la clara visión que tiene, particularmente en el siglo xxI mientras que México presenta un menor avance. Sin embargo, en los últimos años ha estimulado el tránsito del consumo hacia la modalidad electrónica. Se concluye que ambos países deben intensificar su comercio electrónico para pasar definitivamente a la economía de las compras en línea.

Palabras clave: comercio electrónico, transacciones, economía digital, consumo, agentes económicos.

\begin{abstract}
This article analyzes the appearance in the world of electronic commerce, emphasizing the cases of China and Mexico countries that have implemented a series of actions, strategies, programs, and even plans to encourage the use of electronic media and digital in the transactions of economic agents. The findings suggest that China has become a leading country in the use of electronic commerce, thanks to the clear vision it has, particularly in the 21st century, while Mexico presents less progress. However, in recent years it has stimulated the transition from consumption to electronic mode. The article concludes that both countries must intensify their electronic commerce, to transition to the economy of online shopping definitively.
\end{abstract}

Keywords: electronic commerce, transactions, digital economy, consumption, economics agents.

Artículo recibido el 02 de abril de 2020 y dictaminado el 02 de junio de 2020 .

1. Universidad de Colima, Facultad de Economía y Centro Universitario de Estudios e Investigaciones sobre la Cuenca del Pacífico. Av. Gonzalo de Sandoval 444, Col. Las Víboras, C.P. 28040, Colima, Colima, México. ORCID: https://orcid.org/0000-0003-1458-8047 Correo electrónico: jgogar@ucol.mx 


\section{Introducción}

El comercio electrónico es una nueva modalidad del consumo que impacta a las transacciones económicas, particularmente las realizadas por consumidores (familias) y empresas. Es un fenómeno que se presenta a escala global, regional, nacional y local. Esta modalidad poco a poco va ganando terreno en todas las esferas de la economía, tiene entre sus bondades la de permitir a los consumidores contar con un abanico de posibilidades infinitas para realizar sus compras, pues al hacer uso de medios electrónicos, pueden acceder a " $\mathrm{n}$ " sitios web para obtener información que les permita comparar calidad, precio de los bienes y servicios a adquirir e incluso postservicios, fechas de entrega, garantías y plazos de pago.

El comercio electrónico está en un proceso de consolidación como una modalidad predominante, principalmente entre los consumidores. Desde el punto de vista de su evolución, es en las primeras décadas del siglo XXI cuando despega, ello debido a que durante gran parte del siglo Xx su uso era prácticamente nulo, excepto las últimas décadas de éste (Organización para la Cooperación y el Desarrollo Económicos [OCDE], 2000, p. 193). En efecto, en el siglo XXI se ha generado un crecimiento sorprendente del comercio electrónico, pues tan sólo en el año 2017 las ventas mundiales crecieron en 13\%, generando un total de $\$ 29$ billones de dólares en Europa, Asia y Norteamérica, que son los continentes que más destacan en el comercio electrónico (United Nations Conference on Trade and Development [UNCTAD], 2019d, p. 1). En las principales economías de estos territorios se generaron las condiciones para su mayor consolidación, mientras que impactan menos en las economías menos desarrolladas. A pesar del menor impacto, en estas últimas se están generando este tipo de transacciones, impulsadas por el desarrollo de instrumentos jurídicos y tecnológicos que permiten a las transacciones monetarias ser una opción confiable del intercambio.

En un mundo que está transitando de un sistema tradicional en físico o presencial, a otro virtual, de Internet, electrónico u online, se vuelve imprescindible saber qué están haciendo los países para incentivar el comercio electrónico y cómo ello ha evolucionado. En este sentido, los casos de México y China permitirán analizar el desarrollo de esta modalidad de comercio, el cual hasta hace poco tiempo era prácticamente inexistente en ambos y no se percibía que fuera a tener futuro. Sin embargo, los dos países han registrado 
un crecimiento de gran magnitud en comercio electrónico en años recientes, toda proporción guardada, dado el tamaño de ambas economías.

En efecto, en China la aparición del comercio electrónico se presentó a partir de finales de la década de los novena del siglo xx y la primera del xxI, en el año 2000, siendo importante mencionar dos sucesos: por un lado, el cambio relevante en las Tecnologías de la Información y Comunicación (TIC's) (Meng \& Li, 2002, p. 276), y por otro, el ingreso de China a la Organización Mundial del Comercio (OMC) en 2001, hecho que permitió a este país hacer del comercio internacional uno de sus motores del crecimiento económico.

México, por su parte, también comenzó el comercio electrónico entre 1990 y comienzos del siglo xxI. En este periodo se suscitaron algunos acontecimientos importantes como: la revolución digital, que implicó la llegada de computadoras a los hogares, y la democratización de Internet (Mochón, 2014, p. 1); el sistema e-México cuyo objetivo era que la sociedad accediera fácilmente a la información y servicios; así como la reducción de la brecha digital (Lira, 2005, pp. 192-196). Finalmente, la reafirmación de su política comercial internacional de diversificación de mercados.

En los últimos años China está aventajando a México en uso e incremento del comercio electrónico, sobre todo porque al ser la segunda economía del mundo, prácticamente cualquier porcentaje que registre de comercio electrónico es muy grande. Obviamente, México también es una economía a escala internacional relevante, encontrándose en el lugar 15 (Portillo, 2018, p. 1) y que en los últimos años ha presentado progresos importantes en este tipo de transacciones (Asociación Mexicana de Internet [AMIPCI], 2019, p. 5) pero su participación en el comercio electrónico es menor que la de China.

El presente artículo tiene el objetivo de comparar lo que han hecho México y China para incentivar y consolidar el comercio electrónico, lo que permitirá conocer el estado que guarda esta modalidad en cada país. Desarrollar esta modalidad de comercio no es del todo tarea fácil, ya que se requiere formular protocolos de seguridad para aquellas transacciones comerciales y un mejor manejo y conocimiento de las TIC's por parte de los agentes económicos involucrados, así como un marco institucional ad hoc (Rodríguez, 2003, p. 17). La hipótesis que se plantea es que China aventaja a México en la penetración del comercio electrónico, debido a que ha desarrollado un sólido marco normativo, medios electrónicos y de pago para dar certeza a las transacciones electrónicas, pero sobre todo ha desarrollado y aplicado las TIc's a esta modalidad de comercio y a la aceptación de la población de la modalidad. 
Para desarrollar el texto se plantean las siguientes preguntas: ¿cuándo surge el comercio electrónico?, ¿cuándo China y México comienzan a incentivar este comercio?, ¿qué rol han ejercido las Tic's para su desarrollo?, ¿qué perspectivas tiene el comercio electrónico?, ¿qué tiene que hacer México para fortalecer y consolidar el comercio electrónico?

La presente investigación se divide en cinco apartados. El primero lo constituye la presente introducción. En el segundo se describe y analiza el origen, definición y el panorama del comercio electrónico a escala internacional. En el tercero se analiza el contexto y uso del comercio electrónico en China. En el cuarto se hace lo propio para el análisis del comercio electrónico en México. En el quinto se formulan las conclusiones que engloban los hallazgos principales.

\section{Origen, definición y panorama internacional del comercio electrónico}

El comercio electrónico involucra distintas disciplinas del conocimiento científico y tecnológico como la economía, las comunicaciones, los negocios, los servicios, la educación, la informática, las políticas públicas, etc., las cuales a final de cuentas convergen en una misma idea. Turban, Lee, King, McKay y Marshall (2008) definen al comercio electrónico como "el proceso de comprar, vender o intercambiar productos, servicios o información a través de redes informáticas" (p. 4).

La OMC (Organización Mundial del Comercio [OMC], 2020) considera al comercio electrónico como la: "Producción, publicidad, venta y distribución de productos a través de redes de telecomunicaciones" (p. 1). Aguirre y Manasía (2007) plantean que también puede considerarse como "cualquier operación que se desarrolle haciendo uso de redes sociales, en particular de Internet" (p. 39).

La aparición de esta modalidad en el mundo no es muy precisa, se dice que está relacionada con el surgimiento de la Internet en los años sesenta, o aún antes con las transacciones económicas que se realizaron en el puente aéreo de Berlín en 1948 (Zwass, 1996, pp. 3-23). Sin embargo, su uso se estandarizó hasta los años setenta cuando apareció el intercambio de datos electrónicos (EDI, por sus siglas en inglés) cuyo objetivo era el intercambio de documentación entre grandes empresas (Fernández-Portillo, SánchezEscobedo, Hernández-Mogollón \& Jiménez-Naranjo, 2015 p. 108).

Algo que le dio viabilidad al comercio electrónico fue el soporte de ciclo de vida asistido por computadora (Computer Assisted Lifecycle Support, 
CALS) y las transferencias electrónicas de fondos (Electronic Funds Transfer, EFT) que permitían una transmisión electrónica de fondos y la realización de pagos (Tan, Scott, \& Wong, 1999, p. 132). No obstante, la expansión exponencial del comercio electrónico se produjo hasta la década de los noventa con la creación de la tecnología web: World Wide Web (www) en 1992 y la aparición del cifrado de seguridad ssL 3.0 (Secure Sockets Layer) en 1996, debido al progreso que tuvieron las llamadas tecnologías de la información y comunicación (TIC's) (Fernández et al., 2015, pp. 108-109).

Desde que los agentes económicos descubrieron los beneficios del comercio electrónico, se han desarrollado diversas opciones para incentivar su uso, dando así a los consumidores la posibilidad de adquirir bienes tangibles e intangibles; la comodidad de la entrega, ya sea por medio de una transacción totalmente digital (e-commerce, directo) o pedir por Internet; y que su entrega sea física y/o a domicilio (Gutiérrez, 2015, p. 89).

Las formas del comercio electrónico se han clasificado en diversas modalidades, siendo las más conocidas: B2B (empresa-empresa) y B2C (empresaconsumidor) (Gutiérrez, 2015, pp. 89-90). Hay otras como B2G (empresagobierno) y C2C (consumidor-consumidor), incorporando al gobierno y al consumidor típico. Basantes et al. (2016, pp. 43-65) incluyen más modalidades además de las anteriores: G2G, G2B, G2C, C2G, C2B, C2C, B2E, en las que introduce a los empleados (E).

Todas esas modalidades han hecho posible la práctica del comercio electrónico a partir del presente siglo y son las que sintetizan la modalidad de la participación en el comercio electrónico, según el tipo de agente económico que interviene en las transacciones comúnmente empleadas en este tipo de comercio.

En la economía global el comercio electrónico data del siglo xx, al cual se le conoció como la revolución tecnológica, el cual transformó en gran medida la economía a través de la creación de nuevas técnicas comunicativas e informativas, así como determinados avances científicos (Vega, 2016, pp. 220-228). Esto llevó a un gran desarrollo de las redes informáticas, lo que ha tenido como consecuencia el incremento del comercio electrónico, debido a que conforme se consolida, tanto empresas como consumidores hacen uso de éste, sobre todo por medio de la Internet, la cual ha sido fundamental para las transacciones electrónicas.

En el mundo, el comercio electrónico es dominado por los países desarrollados, mientras que en los países en desarrollo apenas ha despertado su 
interés por adentrarse más al comercio electrónico. Tal interés se ha registrado en especial en los países en desarrollo de Asia Oriental (excepto Japón, que fue pionero), subcontinente que se encuentra a la cabeza del comercio electrónico, junto con países de Europa y de Norteamérica (Organización Mundial del Comercio [OMC] y Organización para la Cooperación y el Desarrollo Económicos [OCDE], 2017, pp. 26-30).

Dentro de los continentes, el país líder del comercio electrónico es Estados Unidos, ya que fue uno de los primeros en adoptar esta modalidad, lo que le permitió tomar la delantera en la modalidad B2B en el mundo, lo que se explica por el desarrollo de innovadoras aplicaciones que lo incentivan y grandes avances en la legislación del comercio electrónico que ha promulgado, para brindar mayor seguridad a los participantes en éste (UNCTAD, 2019d, p. 1).

Europa no se ha quedado atrás, ya que ha impulsado el comercio electrónico fortaleciendo sus medidas de seguridad e introduciendo plataformas para su realización; y no se diga de Asia Oriental que, a pesar de introducir el comercio electrónico tardíamente, ha realizado grandes avances, entre ellos su crecimiento en el B2C.

En la figura 1 se observa que los países de Europa, Asia Oriental y Norteamérica lideran las ventas del comercio electrónico mundial, siendo Estados Unidos el país que representa más del 30\%, seguido por Japón y China, siendo este último país quien ha logrado aproximarse a Estados Unidos en la modalidad B2C, con $27 \%$ de este tipo de comercio.

\section{Figura 1}

Países que más utilizan el comercio electrónico a nivel mundial, 2017

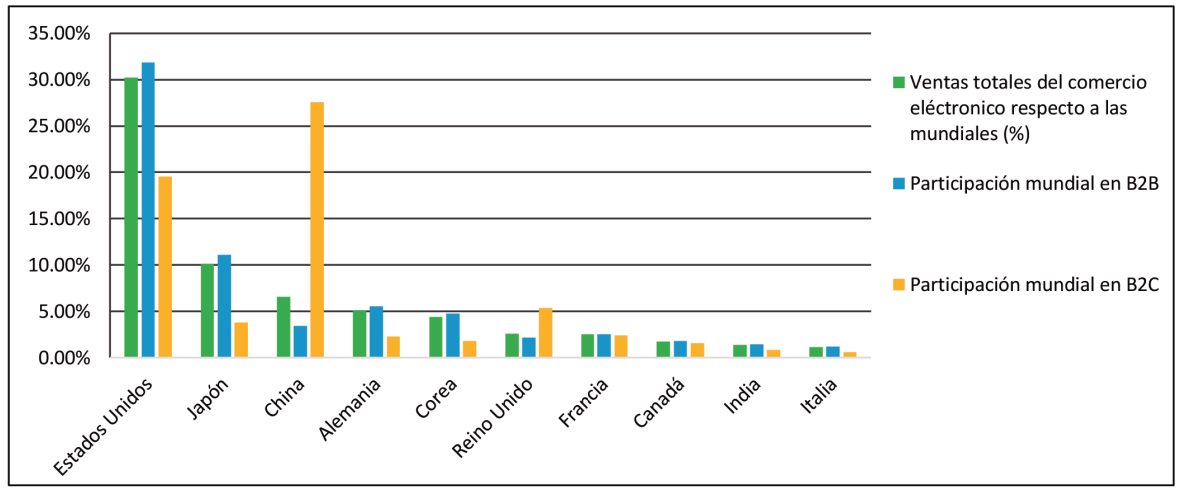

Fuente: elaboración propia con datos de UNCTAD (2019a, p. 15). 
Frente al avance de estos países en el comercio electrónico, otros países en desarrollo de América, África y Oceanía han presentado un avance más lento, sobre todo en África, ya que tan sólo el $26 \%$ de la población usa Internet; mientras que en América Latina y el Caribe $(\mathrm{ALyC})$ un poco más del $50 \%$ de la población lo usa (figura 2). Por regiones, ALyC está en cuarto lugar, lo que expresa un retraso en el desarrollo de infraestructura e Internet (Sánchez \& Arroyo-Cañada, 2016, p. 142).

Figura 2

Porcentaje de la población que utiliza Internet, 2018 (\%)

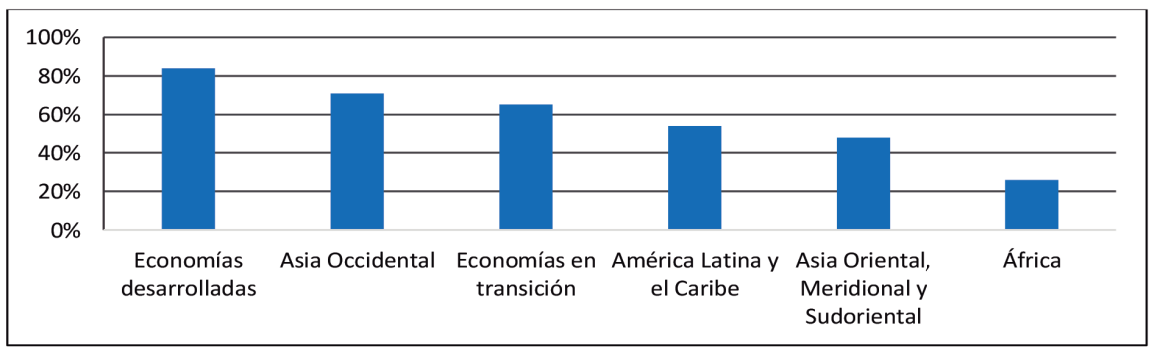

Fuente: elaboración propia con datos de UNCTAD (2019c, p. 4).

Como se puede intuir, el comercio electrónico difiere de un continente a otro; de una economía a otra. Esto expresa la existencia de una brecha digital enorme en el acceso y uso de las TIC's entre países. Por un lado, los países desarrollados, que cuentan con infraestructura de TIC's se caracterizan por poseer una mayor capacidad de exportar y ser productores de altas tecnologías, equipos y maquinarias; mientras que los países subdesarrollados presentan en general la necesidad de importar bienes y servicios tecnológicos; baja productividad; mano de obra poco calificada y escasa tecnología (González \& Rodríguez, 2008, p. 1).

Las diferencias en nivel de desarrollo de los países ayudan a comprender las causas de la brecha digital, debido a que los países desarrollados que producen estas tecnologías tienen mayor acceso a las mismas; mientras que los países menos desarrollados presentan un menor acceso a las Tic's y por ende menor uso del comercio electrónico. A pesar de ello, el comercio electrónico ha despuntado en las transacciones de empresas y consumidores en las economías subdesarrolladas, en parte gracias a que organismos globales 
organizan conferencias y foros internacionales para ayudarles a resolver problemas relacionados con el comercio electrónico, como la contratación, la propiedad intelectual y la tributación (Vega, 2016, p. 233).

Así, los países subdesarrollados están logrando avanzar en esta modalidad, creando instrumentos jurídicos y tecnológicos para obtener mejores resultados en el comercio electrónico (figura 3). De hecho, países de Asia Oriental y de $\mathrm{ALyC}$ se encuentran en proceso de incrementar la seguridad en esta modalidad.

\section{Figura 3}

Economías con legislación sobre comercio electrónico, por regiones, 2018

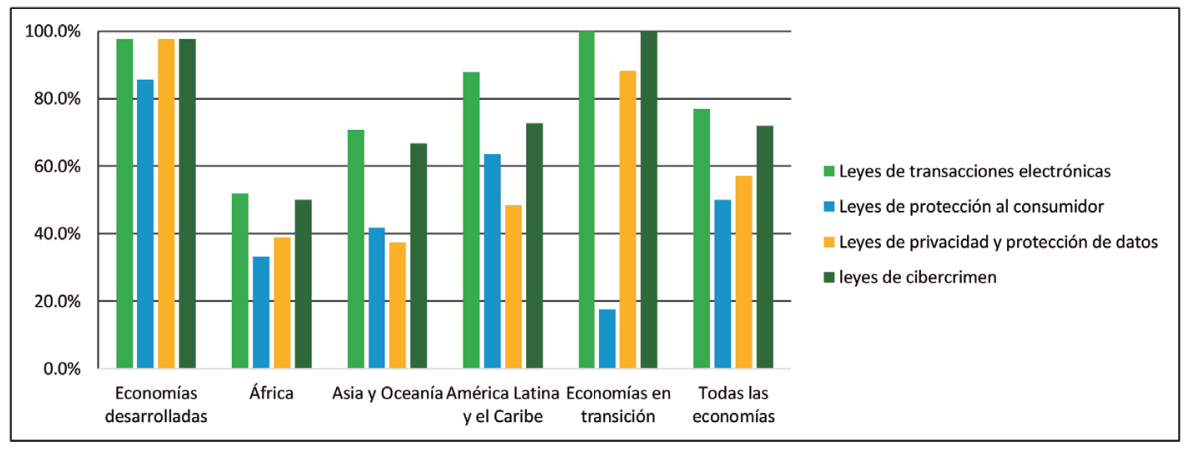

Fuente: elaboración propia con información de UNCTAD (2020).

En ese sentido, la Conferencia de las Naciones Unidas sobre Comercio y Desarrollo (UNCTAD, por sus siglas en inglés) (2019b, pp. 5-38) pretende impulsar y mejorar el comercio electrónico a nivel mundial. Para tal efecto, organizó la semana del comercio electrónico en 2019, en la que se trataron temas referentes a la manera en que el comercio electrónico contribuye al desarrollo de los países, el cómo seguir impulsando el e-Trade for all, así como el e-Trade for Women; además de buscar una reducción de la brecha digital, una mayor transformación digital así como una mayor seguridad, garantizando la privacidad de los datos y la propiedad intelectual.

Para los países en desarrollo, la UNCTAD (2019e, p. 1) especialmente enfatizó la evaluación rápida de la preparación del comercio electrónico ( $e T$ Ready, por sus siglas en inglés), con la finalidad de ayudarlos a identificar los obstáculos al desarrollo de dicha modalidad; también, el análisis de las áreas de mejora, entre ellas: contar con una mayor disponibilidad de infraestructura digital, acceso a Internet, alfabetización digital, reforzar las políticas digitales, 
fomentar la inclusión financiera y contar con acceso a métodos de pago, educación, habilidades, seguridad en línea, logística y facilitación del comercio.

A manera de colofón de esta sección, se tiene que el comercio electrónico ha evolucionado bastante en el mundo, aunque obviamente de manera diferenciada: mayor avance en los países desarrollados y menor en los subdesarrollados. De ahí la importancia de que estos últimos diseñen una estrategia y acciones para disminuir la brecha, pero sobre todo que generen las condiciones e infraestructura física, de TIC's e institucional, que permita a la población tener acceso generalizado a esta nueva modalidad de comercio. A continuación se analiza el caso país, que nos permitirá conocer cómo surge y evoluciona el comercio electrónico en China.

\section{Contexto del comercio electrónico en China}

China adoptó una estrategia de desarrollo de las TIC's en 1980 y la vio como un camino hacia la modernización y desarrollo económico, lo que le hizo impulsar la creación de proyectos "dorados", entre ellos la tarjeta dorada y el puente dorado; la primera servía como dinero electrónico para impulsar la banca electrónica y el segundo era una red de información sobre comercio exterior. Esta estrategia generó aumentos en el uso de las TIC's, sobre todo por el incremento de usuarios de Internet, aunque todavía no había un uso importante en las transacciones en línea (UNCTAD, 2001, pp. 62-65).

Fue en el año 1987 cuando el profesor Qian Tianbai envió el primer correo electrónico en China, cuando comenzó el desarrollo de Internet en el país. En 1994 China logró la primera conexión exitosa con Estados Unidos y al año siguiente las familias ya tenían acceso a Internet. A partir de ese momento comenzaron a crearse portales electrónicos como Sina, Sohu y Netease, e incluso en 1998 se desarrollaron motores de búsqueda como Baidu y Tencent, así como sitios web de comercio electrónico como Alibaba, quien más tarde lanzó Taobao y Alipay. Esto focalizó el modelo de comercio electrónico, el cual, representado por el comercio minorista, logró empujar al país a la economía digital (Rihui \& Hongxia, 2018, pp. 30-32).

De esa manera, y, sobre todo después del ingreso de China a la OMC en 2001, se comenzaron a plantear los compromisos de liberalización de servicios financieros y de telecomunicaciones, mismos que crean condiciones de competencia que reducen los costos de acceso y estimulan el desarrollo del comercio electrónico (UNCTAD, 2001, pp. 62-65). Desde entonces China ha 
crecido a un gran ritmo en el desarrollo y uso de las Tic's. Esto se observa la figura 4, donde el comercio electrónico ha crecido de manera exponencial hasta llegar a los $\$ 29$ billones de yuan renminbi (RMB) en 2017. Por años China ha impulsado la innovación para el desarrollo, siendo el comercio electrónico y los pagos por medio del teléfono móvil de los más usados (Xinhua, 2018a, p. 1).

Figura 4

Comercio electrónico de China, 2004-2017 (Billones de RMB)

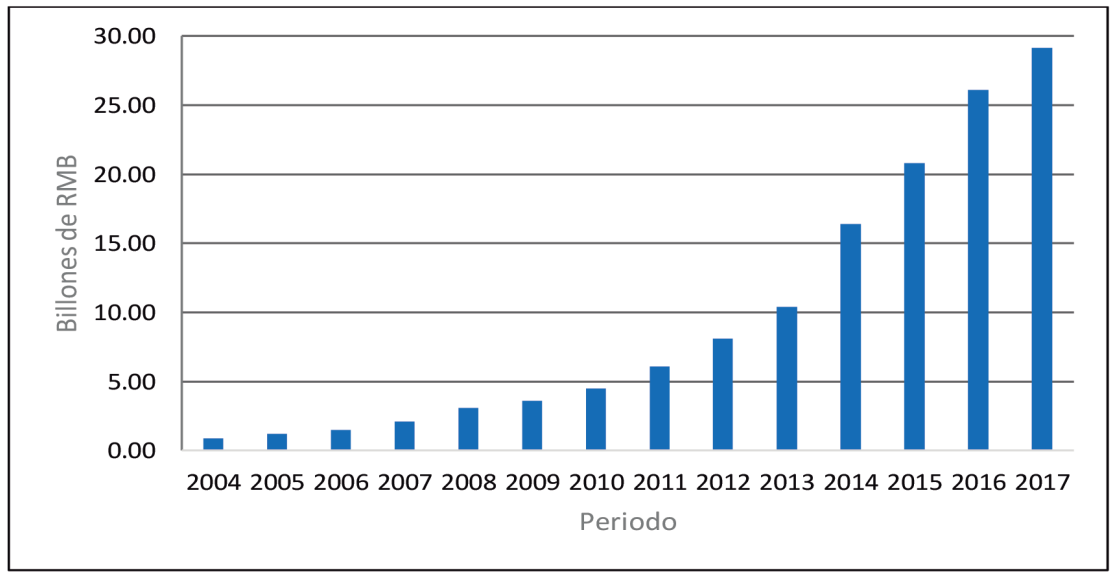

Fuente: elaboración propia con información de Hongfei (2017); Rihui y Hongxia (2018).

En China los teléfonos móviles son el medio más popular para realizar transacciones comerciales, las cuales han presentado una tendencia ascendente desde que el país comenzó a introducir esta modalidad. El uso de la frase: "los móviles para todo" es realmente popular y se usa desde para hablar o mandar mensajes, hasta para pedir comida, un taxi, hacer compras en el supermercado o una cita médica (Xinhua, 2017b, p. 1). Esto se ve reflejado en la figura 5 , donde el 99\% de los internautas chinos acceden a Internet a través de su teléfono móvil, cerca del $50 \%$ a través de una computadora y alrededor del $30 \%$ mediante laptops, televisión o tableta. 


\section{Figura 5}

Uso de dispositivos de acceso a Internet en China, 2018-2019 (\%)

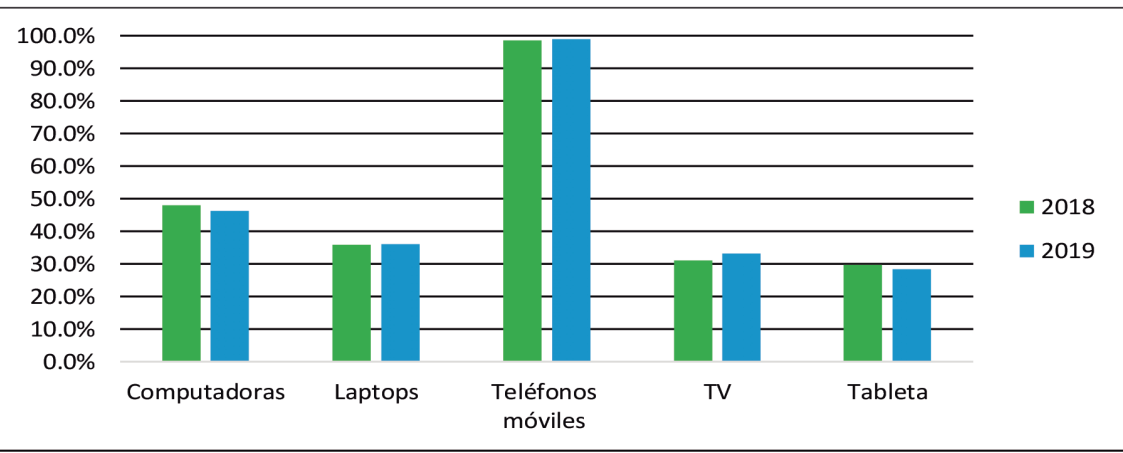

Fuente: elaboración propia con información de CNNIC (2018, pp. 6-10); CNNIC (2019, pp. 7-8).

El incremento de la participación del comercio electrónico ha sido relevante. En efecto, entre el 80 y $90 \%$ de la población está utilizando Internet para los mensajes instantáneos, búsquedas diversas de noticias, videos, música, juegos, literatura, cine, arte, etc., mientras que entre 60 y $75 \%$ lo utiliza para compras en línea o pagos, y cerca del $50 \%$ para reservar viajes u ordenar comida (China Internet Network Information Center [CNNIC], 2019, pp. 21-22).

Por su parte, las empresas incorporan cada vez más el uso de las TIC's a sus modelos de negocio, puesto que más del $90 \%$ de las empresas cuentan con una computadora, la cual usan para publicitarse, vender e incluso capacitar y contratar empleados; y finalmente, el gobierno, que es el usuario por excelencia, se ha enfocado en ofrecer y mejorar sus servicios a la población, de tal manera que en 2019 logró que cerca del 60\% de los internautas usaran los servicios de la administración electrónica china (CNNIC, 2019, p. 58).

Asimismo, se han sumado más usuarios de Internet en los últimos años, al pasar de 384 millones en 2009 a 854 millones en 2019, cantidad que representa más de la mitad de la población China, lo cual se dice fácil, pero la dimensión de tal logro se magnifica si se tiene en cuenta que en 2005 había poco más de 100 millones de usuarios (figura 6). 


\section{Figura 6}

Usuarios de Internet en China, 2005-2019 (10,000 personas)

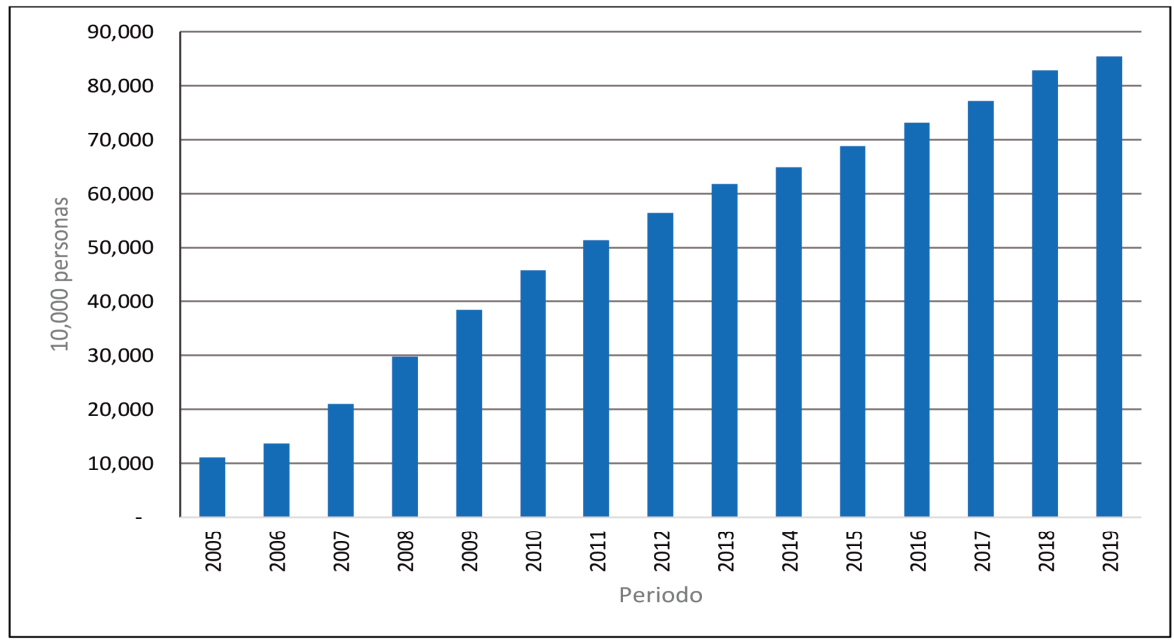

Fuente: elaboración propia con información de NBSC (2020); y CNNIC (2019, p. 13).

A pesar de los avances mostrados por China líneas arriba, en este país como en el resto del mundo existen brechas digitales como la brecha rural-urbana. En efecto, en 2019 las zonas urbanas registraron a más del 70\% de los usuarios de Internet; las rurales el 26.3\%. Esta disparidad representa un obstáculo para el comercio electrónico. Las principales razones por las que no se puede acceder a esta modalidad son la logística y las transacciones; la primera por la falta de servicios de entrega de paquetería express por las empresas de mensajería rápida, en la mayor parte del campo, y la segunda debido a que muchos habitantes de pueblos y villas no están familiarizados con las plataformas en línea o tienen poco acceso a los medios de pago en línea y desconfían de las transacciones electrónicas (Couture, Faber. Gu, \& Liu, 2017, pp. 2-4).

Para incrementar la economía digital en el campo, el gobierno asumió como prioridad de la política nacional el reducir la brecha económica ruralurbana. Por ello diseñó algunas estrategias e implementó algunas acciones, como el haberse asociado con una de las grandes empresas chinas de comercio electrónico, misma que se encargó de la construcción de almacenes para una más eficiente distribución de los paquetes rurales, así como el otorgamiento de subsidios al transporte entre las ciudades y aldeas, con el fin de llevar el 
comercio electrónico a zonas rurales, sin afectar el precio ni la calidad. Respecto a la barrera transaccional, el programa instala una terminal de comercio electrónico en un pueblo central, de la cual se encarga un gerente de la empresa, quien ayuda a los residentes a realizar transacciones en el comercio electrónico (Couture et al., 2017 pp. 2-7).

Los esfuerzos de China por hacer llegar el comercio electrónico a todo el país han tenido un impacto positivo, puesto que los campesinos se han interesado más por hacer uso del comercio electrónico, lo que generó que alrededor de 9.8 millones de empresas participaran en esta política para reducir la brecha tanto en el área rural de la región oriente, como la del noroeste; dentro de estas empresas se encuentra Tabao, que ha llegado a 29 provincias, dando cobertura a cerca de 600 condados y 30,000 aldeas (Xinhua, 2018b, p. 1; Li, 2017, pp. 57-62).

Grosso modo se podría afirmar que tanto el número de usuarios de Internet como el comercio electrónico han observado una tendencia ascendente en China, impulsados principalmente por las acciones llevadas a cabo por el gobierno, no sólo en zonas urbanas sino también en las rurales, lo que ha generado una mayor cobertura y alcance de las tecnologías y nuevos entrantes, tanto al uso de Internet como a las transacciones electrónicas.

Efectivamente, en años recientes, considerando a los usuarios de Internet por género, edad, origen, grado escolar; por acceso a la información buscada, se tiene que: los hombres representaron el $52.4 \%$; y las mujeres el $47.6 \%$; la edad promedio se encuentra en el rango etario de 10-49 años. Por nivel educativo, predomina el nivel secundaria; siendo su ocupación principal el estudiar y algunos son empresarios autónomos. El 90\% de los usuarios accede a Internet desde casa; mientras que el resto lo hace desde su trabajo o sitios públicos como lo son las escuelas, bares, ciber, entre otros. Estos consumidores utilizan Internet en mayor medida para mensajes instantáneos, búsquedas, noticias, videos, música, pagos, compras, juegos, banco y viajes; y en menor medida para foros, financiamiento y cursos. Los aparatos electrónicos más utilizados para la conexión son los teléfonos móviles con el 99.1\%; seguido de las computadoras de escritorio (46.2\%) y laptops (36.1\%). En cuanto a compras en línea, el número de usuarios llegó a 854 millones en 2019 con una penetración de Internet del 61.2\% (CNNIC, 2019, pp. 13-55).

Respecto a la seguridad, los usuarios de Internet se han encontrado con inconvenientes al momento de realizar sus transacciones, siendo el más común el fraude en línea, seguido de los dispositivos infectados por virus, cuentas o 
códigos robados e información personal filtrada. Dentro del fraude en línea se encuentra el fraude en la información, de compras en línea o sitios web de phishing (suplantación de identidad para estafar), entre otros (CNNIC, 2019, pp. 72-73).

El gobierno ha llevado a cabo diferentes estrategias para mejorar la seguridad de los usuarios, lo que ha permitido registrar grandes progresos para el comercio electrónico. Por ejemplo, ha legislado mucho en materia de comercio electrónico; desde sus comienzos hasta la fecha ha publicado muchas leyes específicas. De acuerdo con la UNCTAD, China cuenta con una ley de transacciones electrónicas, dos leyes para la protección del consumidor en línea, una ley del cibercrimen, así como una para la protección de datos y privacidad. Asimismo, recientemente elaboró la ley del comercio electrónico, en la que se trata la protección a los derechos de los consumidores para darles más seguridad al momento de realizar compras (Xinhua, 2017a, p. 1).

Asimismo, los usuarios de Internet han aprovechado las oportunidades que les brinda el comercio electrónico y han incrementado sus compras, sobre todo en las temporadas de grandes promociones y ofertas, en especial con el famoso doble 11 o mejor conocido como el día del soltero, que es una de las modas y tendencias más populares de China (Bali, 2018, p. 2).

China incentiva la economía digital constantemente, por lo que busca diversas estrategias para consolidar el comercio electrónico apoyando algunas tendencias que se están presentando en el país, como el modelo "online to offli$n e$ " (O2O), en donde el consumidor solicita por Internet y se recibe fuera de Internet, es decir, se recibe físicamente el bien o servicio y se paga en efectivo o en línea. Otra característica del comercio electrónico está asociado con los pagos digitales, siendo los más populares Alipay y WeChat, que forman parte integral de plataformas como Alibaba y JD.com. Por último, se tiene el uso y desarrollo de la plataforma en línea a la plataforma de medios, las que están permitiendo a los usuarios no sólo utilizar las redes sociales para interactuar, sino también para publicitar productos (Bali, 2018, p. 6).

Por otro lado, existen tres tendencias relevantes que se están registrando en el país, destacando entre ellas: el mayor uso del móvil, el comercio social y el comercio electrónico transfronterizo. El uso del móvil es todo un fenómeno debido a la mayor participación de los usuarios de Internet y de las empresas mediante la creación de aplicaciones para pagos en línea, por medio de celulares. De hecho, en Asia, China es el país líder en el uso del teléfono móvil para realizar transacciones electrónicas (Nielsen, 2016, pp. 5-7). 
El comercio social involucra el uso de las redes sociales para las transacciones en línea de bienes o servicios y el sistema de pagos con base en los códigos QR (Zhong, 2012, pp. 1-2). Este tipo de transacciones usan las plataformas más populares como WeChat que abarca el $80 \%$, Qzone (60\%) y Weibo (40\%), que han dado un impulso definitivo al comercio electrónico (cNNIC, 2018, p. 34).

Por último, está el comercio electrónico transfronterizo, es decir, aquellas transacciones electrónicas entre los consumidores y proveedores de diferentes países, que están haciendo uso de plataformas de comercio electrónico (Wang, Wang, \& Lee, 2017, pp. 1-2). Esta modalidad es la principal aportación del comercio electrónico para expandir el comercio internacional y en China. Dicho comercio electrónico adquiere cada vez más importancia, lo que se ha reflejado en políticas gubernamentales que lo fomentan e incentivan.

El mismo gobierno está incrementando paulatinamente la economía digital, al grado de representar alrededor del $20 \%$ del total de las transacciones electrónicas en el país, considerando tanto en las aplicaciones, en sitios web, como en los blogs. En 2019 China tuvo 14,142 páginas del gobierno electrónico, destacando las provincias de Sichuan, Henan y Shandong como las provincias con más sitios gubernamentales. Dos de los sitios más utilizados por el gobierno son Weibo y WeChat, utilizándolos para temas referentes a la seguridad pública, justicia, gobierno, industria, comercio e impuestos (CNNIC, 2019, pp. 21-55).

No obstante su menor proporción en la participación en el uso del comercio electrónico, el gobierno chino ha sido un factor fundamental para el desarrollo y fortalecimiento de éste. En efecto, en el presente siglo ha llevado a cabo proyectos e implementado reglas para promover el comercio electrónico. La primera legislación del comercio electrónico fue la Ley de Firma Electrónica de la República Popular de China, que entró en vigor el 1 de abril de 2005 con el fin de regular este tipo de comercio, así como para validar las firmas electrónicas y proteger los derechos e intereses legítimos de las partes interesadas (Xiang \& Jing, 2014, p. 80).

Grosso modo, algunas de las acciones más relevantes para incentivar el comercio electrónico que ha realizado China, han sido las siguientes: en el año 2007 lanzó el primer plan de desarrollo de comercio electrónico en el contexto y soporte del xi periodo quinquenal (2006-2010); en 2009 especificó el modelo e-business para establecer estándares para los negocios de comercio electrónico con el fin de defender los intereses de los consumidores; en 2010 llevó a cabo medidas de administración sobre el comercio de productos bási- 
cos en línea y sobre el servicio de pago de instituciones no financieras para regular las actividades en línea y mejorar los servicios de pago en línea; en 2011 planteó el establecimiento de una serie de ciudades modelo de comercio electrónico en toda China y se emitieron circulares para regular las compras en línea y combatir las infracciones de propiedad intelectual; en 2012 incentivó a las grandes empresas minoristas para que establecieran tiendas en línea; en 2013 emitió una circular sobre la promoción de un desarrollo sano y rápido del comercio electrónico y una ley orientada a la protección de los consumidores; en 2014 estableció las medidas administrativas para el comercio en línea (Xiang \& Jing, 2014, pp. 81-83).

En años recientes (2015-2019) el gobierno chino ha enfocado sus programas en promover el consumo en línea, crear programas de educación y capacitación para el comercio electrónico, fomentar el comercio electrónico transfronterizo y la elaboración de borradores para la Ley del Comercio Electrónico en China, misma que entró en vigor en 2018.

Lo anterior se puede observar en la tabla 1 , donde se muestra un listado de las políticas gubernamentales del comercio electrónico más importantes en China. El éxito del país en esta modalidad se debe sobre todo a los objetivos del gobierno por incentivar el uso de los medios electrónicos de esta modalidad; la implementación de medidas de control y vigilancia, para seguridad de los ciudadanos; y el impulso a las grandes innovaciones para mejorar los servicios; lo que favorece tanto a los usuarios existentes como a nuevos entrantes a este tipo de comercio. 


\section{Tabla 1}

\section{Políticas gubernamentales sobre el comercio electrónico en China, 2005-2018}

\begin{tabular}{|c|c|c|}
\hline Fecha & Programas & Descripción \\
\hline \multirow[t]{4}{*}{$2005-2010$} & Ley de la firma electrónica. & $\begin{array}{l}\text { Estandarizar los actos de la firma } \\
\text { electrónica. }\end{array}$ \\
\hline & $\begin{array}{l}\text { Plan de desarrollo de comercio } \\
\text { electrónico durante el } 11^{\circ} \text { periodo } \\
\text { quinquenal. }\end{array}$ & $\begin{array}{l}\text { Impulsar el desarrollo del comercio } \\
\text { electrónico en China, haciendo } \\
\text { más populares las transacciones } \\
\text { electrónicas. }\end{array}$ \\
\hline & Especificación del modelo e-business. & $\begin{array}{l}\text { Establecer estándares para los } \\
\text { negocios de comercio electrónico con } \\
\text { el fin de proteger los intereses de los } \\
\text { consumidores. }\end{array}$ \\
\hline & $\begin{array}{l}\text { Medidas de administración } \\
\text { provisional sobre el comercio } \\
\text { de productos básicos en línea y } \\
\text { actividades de servicios conexos. }\end{array}$ & $\begin{array}{l}\text { Regular las actividades en línea } \\
\text { respecto a las obligaciones de las } \\
\text { empresas que comercializan. }\end{array}$ \\
\hline \multirow[t]{5}{*}{ 2011-2015 } & $\begin{array}{l}\text { Opinión de guía sobre el inicio de } \\
\text { la creación de ciudades modelo de } \\
\text { comercio electrónico en China. }\end{array}$ & $\begin{array}{l}\text { Establecer una serie de ciudades } \\
\text { modelo de comercio electrónico en } \\
\text { toda China. }\end{array}$ \\
\hline & $\begin{array}{l}\text { Opiniones de guía sobre la promoción } \\
\text { del desarrollo del comercio minorista } \\
\text { durante el } 12^{\circ} \text { periodo del plan } \\
\text { quinquenal. }\end{array}$ & $\begin{array}{l}\text { Apoyar a las grandes empresas } \\
\text { minoristas para que establezcan } \\
\text { tiendas en línea. }\end{array}$ \\
\hline & $\begin{array}{l}\text { Circular para mejorar la promoción } \\
\text { de un desarrollo sano y rápido del } \\
\text { comercio electrónico. }\end{array}$ & $\begin{array}{l}\text { Impulsar la innovación en el } \\
\text { sector del comercio electrónico y } \\
\text { promover un entorno seguro para las } \\
\text { transacciones en éste. }\end{array}$ \\
\hline & $\begin{array}{l}\text { Enmiendas a la Ley de Protección al } \\
\text { Consumidor de China. }\end{array}$ & $\begin{array}{l}\text { Se centra en una mejor protección } \\
\text { de los derechos e intereses de los } \\
\text { consumidores. }\end{array}$ \\
\hline & $\begin{array}{l}\text { Medidas administrativas para el } \\
\text { comercio en línea. }\end{array}$ & $\begin{array}{l}\text { Establecer regulaciones para el } \\
\text { comercio en línea y proteger los } \\
\text { derechos de las partes involucradas. }\end{array}$ \\
\hline
\end{tabular}




\begin{tabular}{l|l|l}
\hline Fecha & Programas & Descripción \\
\hline 2016-2018 & $\begin{array}{l}13^{\circ} \text { plan quinquenal de desarrollo } \\
\text { para el comercio electrónico. }\end{array}$ & $\begin{array}{l}\text { Fortalecer el desarrollo del comercio } \\
\text { electrónico, así como descubrir e } \\
\text { investigar violaciones de las leyes y } \\
\text { reglamentos a tiempo. }\end{array}$ \\
\cline { 2 - 3 } & $\begin{array}{l}\text { Borradores de la Ley de Comercio } \\
\text { Electrónico. }\end{array}$ & $\begin{array}{l}\text { El objetivo es regular el sector de } \\
\text { comercio electrónico de China para } \\
\text { facilitar su crecimiento, mantener } \\
\text { el orden de mercado y disminuir } \\
\text { fraudes. }\end{array}$ \\
\cline { 2 - 3 } & Ley del Comercio Electrónico. & \\
\hline
\end{tabular}

Fuente: elaboración propia, con información de Xiang y Jing, (2014, pp. 81-83); Yi (2017, pp. 17-22); Information Office of the Ministry of Commerce (2017); Xinhua (2017a, p. 1).

\section{Situación del comercio electrónico en México}

Formalmente, la Internet en México surgió en 1987 cuando la Universidad Nacional Autónoma de México (UNAM) estableció la primera conexión a través del Instituto Tecnológico de Monterrey a un servidor en San Antonio, Texas, en Estados Unidos, pero no fue sino hasta 1990 cuando comenzaron las conexiones públicas y privadas, lo que fomentó la aparición de nombres de dominios registrados. En 1992 sólo existía el dominio "mx", y al siguiente año surgieron los subdominios "com.mx" y "gob.mx". De esa manera, el comercio electrónico nació en el país en 1993 con la creación de "com.mx", provocando que las empresas usaran Internet para las transacciones comerciales (Palacios, 2003, p. 70).

No obstante, durante el siglo xx el uso de las Tic's y el acceso a Internet era limitado, sobre todo por el poco acceso y desconocimiento del manejo de los medios de comunicación digitales, como las computadoras o celulares, y por el alto costo de las conexiones y de los aparatos clave: computadoras de escritorio, laptops y handbooks, etc., razón por la cual existían pocos usuarios de Internet (Quintanilla, 2003, pp. 3-4).

A partir del año 2000 se dio el gran salto hacia la adopción de las nuevas tecnologías, apoyado sobre todo por el gobierno a través de diferentes programas, entre ellos el programa "Precisa", con el que se dio acceso a la información del gobierno mexicano; y el "Sistema Nacional e-México" cuya finalidad era crear una economía más digital, acelerando el uso de las TIC's por parte de la población mediante mayor conectividad, contenidos y sistemas de alta velocidad en el país. Tal sistema incluía dos proyectos: e-local 
y e-gobierno; el primero destinado a brindar servicios de gobierno, salud, aprendizaje, y el segundo como una plataforma del gobierno en donde se aplican dos clasificaciones del comercio electrónico, que son de gobierno a ciudadano y de ciudadano a gobierno, sin intermediarios (Quintanilla, 2003, pp. 6-7; Ordóñez, 2003, pp. 58-64).

Las TIC's han transformado a la sociedad universal, y la mexicana no es la excepción. Ello ha provocado que los agentes económicos se adapten al uso de Internet y se beneficien de éste a través el comercio electrónico (Cázares \& López, 2013, p. 2). El uso de las TIC's en México es cada vez más notorio; conforme pasa el tiempo, más hogares poseen equipamiento de TIC's (computadoras, pantallas Led, tabletas, laptops, teléfonos inteligentes, etc.) y, por ende, el uso de Internet se incrementó, tal como se observa en la figura 7, en la cual en 2009 había 27 millones de usuarios, mientras que en 2019 se alcanzaron los 80 millones de usuarios de Internet, es decir, en tan sólo 10 años el uso de Internet casi se triplicó. En comparación con China, esta cantidad representa casi el 10\% de los usuarios chinos de Internet.

\section{Figura 7}

Usuarios de Internet en México, 2001-2019 (Millones de usuarios)

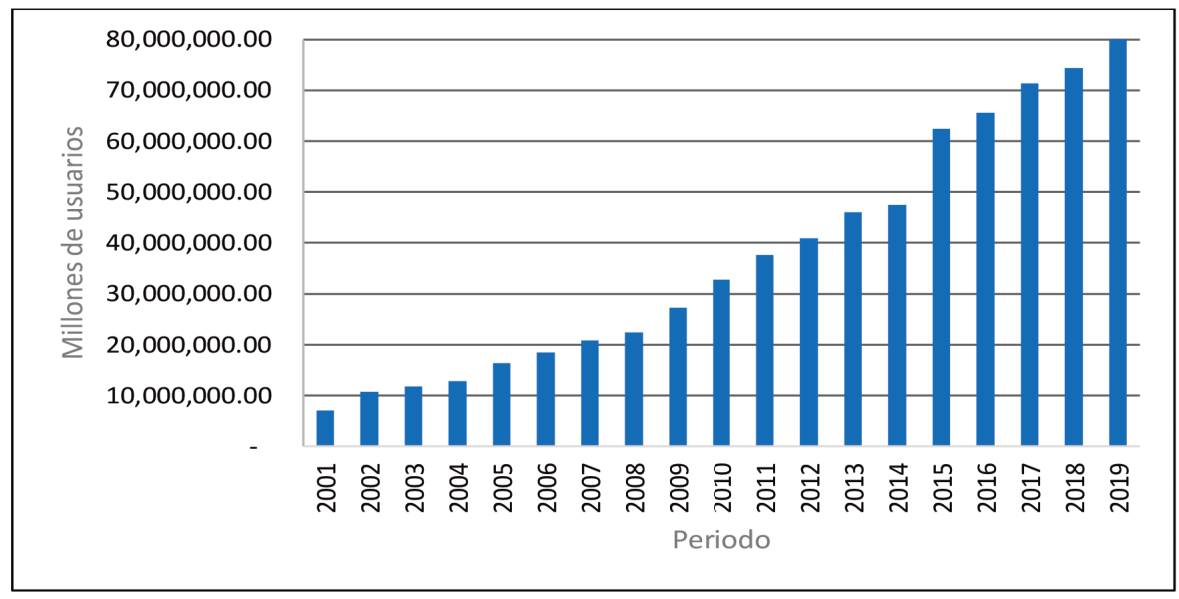

Fuente: elaboración propia con datos del INEGI (2020, p. 5).

Con el crecimiento y mayor uso de las TIC's se ha incentivado el comercio electrónico, el cual ha cambiado la manera de comerciar y contratar, ya que 
la introducción de los medios electrónicos dio un giro hacia nuevas formas de comerciar, modificando el ámbito en que se realizan las transacciones, los métodos para hacerlas seguras y formalizar a los agentes que realizan el intercambio (Ríos, 2014, p. 102). En México, como en el mundo, las transacciones electrónicas son cada vez mayores; en 2009 éstas sumaron $\$ 24.5$ miles de millones de pesos, mientras que en 2018 sumaron $\$ 491.25$ miles de millones de pesos (véase figura 8).

\section{Figura 8}

Evolución del comercio electrónico en México, 2009-2018

(Miles de millones de pesos)

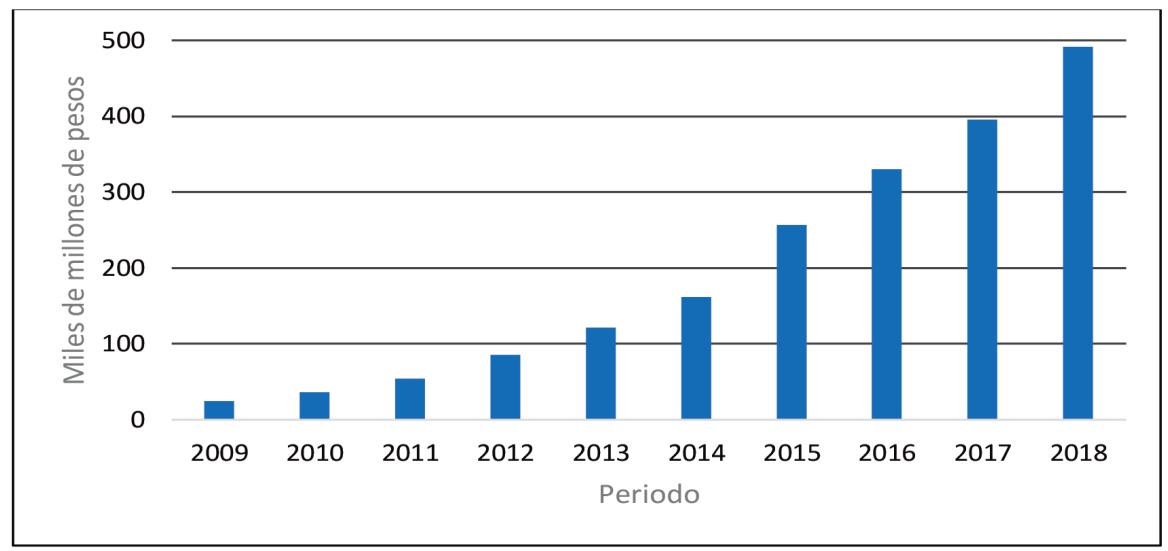

Fuente: elaboración propia con datos de AMIPCI (2019: 5).

No sólo se ha incrementado el volumen del comercio electrónico, sino también su participación en el Producto Interno Bruto (PIB) de la economía, lo cual nos indica la relevancia que tiene el uso de las nuevas tecnologías en el país, tal como se observa en la figura 9, en la cual la participación del comercio electrónico en el PIB pasó de 3\% en 2013 a 5\% en 2018, incrementando en dos puntos porcentuales el PIB en tan sólo cinco años, destacando en dicho aumento una serie de servicios y sobre todo el uso del comercio al por mayor. 


\section{Figura 9}

Participación del comercio electrónico en el PIB de México, 2013-2018 (\%)

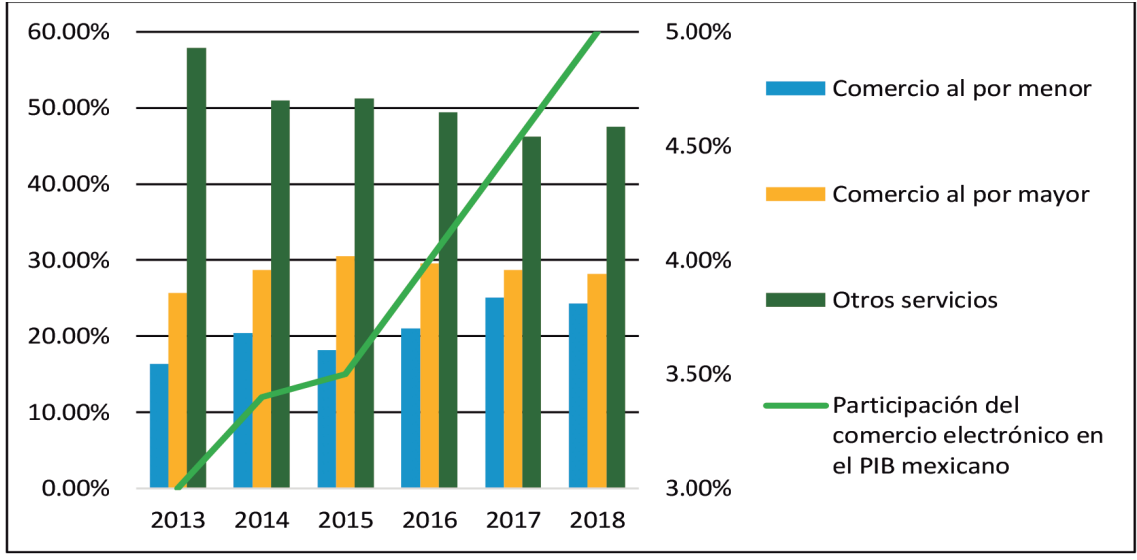

Fuente: elaboración propia con datos del INEGI (2020 p. 1).

Por otra parte, es importante mencionar a los compradores en línea, quienes son una parte esencial en el comercio electrónico. En 2019, la mayoría de los compradores en línea estuvieron representados por mujeres (51\%), seguidas de los hombres (49\%), siendo el $74 \%$ de éstos mayores de edad, destacando el rango de 25-44 años. Su nivel socioeconómico es medio alto o medio bajo y su lugar preferido para conectarse es en el hogar, trabajo u otro. Su gasto va orientado al transporte, comida rápida, alojamiento, viajes, boletos de eventos, descargas y servicios digitales, ropa y accesorios, despensas del supermercado y pasatiempos; la mitad de los compradores hacen compras internacionales en Estados Unidos (64\%), Asia (29\%) y Europa (21\%) (AMIPICI, 2019, pp. 9-14).

Los métodos de pago que más utilizan son a través de tarjetas bancarias, seguidos por los físicos, con dinero en efectivo; los tres tipos de pago online más populares son la tarjera de crédito, de débito e intermediarios bancarios como PayPal, mientras que los pagos offline son tiendas de conveniencia Oxxo, farmacias particulares, depósitos bancarios o en supermercados. La mayoría de los compradores que realizan el pago en línea, esperan el pedido directo en su hogar (80\%). La satisfacción de los compradores en línea es buena, ya que éstos están en $84 \%$ satisfechos; al momento de realizar la compra se interesan por factores importantes, entre ellos el precio, información, rapidez 
de entrega del producto, seguridad en la transacción y variedad en las formas de pago (AMIPCI, 2017a, pp. 27-28; AMIPCI, 2019, pp. 18-25).

Otro de los agentes económicos importantes en el comercio electrónico son las empresas. En México hay cuatro principales modelos de negocios empresariales; el primero es la venta retail (al por menor), ofreciendo productos o servicios con entrega rápida; el segundo son las subastas, ya sea de productos nuevos o de segunda mano; el tercero es Marketplace, en el que se ofrecen productos de distintos vendedores o fabricantes, siendo intermediario de compradores y vendedores; el cuarto es la suscripción, donde el consumidor contrata un producto o servicio y realiza pagos por el tiempo de uso (Asociación Mexicana de Venta Online [AMvo], 2018, pp. 1-2).

En México se ofrecen incentivos para que las empresas se interesen más en el comercio electrónico, uno de ellos son los premios al comercio electrónico, también conocido como " $e$-commerce award", en donde se reconoce a las empresas líderes en comercio electrónico de acuerdo con su negocio. En 2019, las líderes fueron Interjet (viajes), Bestbuy (retail), Cinépolis (entretenimiento), Mercado pago (banca en línea), Conekta (servicios y soluciones), Troquer (moda), entre otras (Ecommerce Institute, 2019, p. 1).

Asimismo se llevan a cabo nuevas campañas especiales para aumentar las compras en línea. Las empresas deben estar preparadas para las temporadas altas de las compras; anteriormente sólo existían las fechas festivas, como: el Día de los Reyes Magos, el Día de San Valentín, el Día del Niño, Día de las Madres, Día del Padre, las Fiestas Patrias, Día de Muertos o Navidad, pero a partir del uso de las tecnologías, llegan las nuevas campañas ofreciendo descuentos y promociones; las principales en México son: Ventas Nocturnas, Hot Sale, Buen Fin, Hot Monday, por mencionar algunas (AMvo, 2018, pp. 3-4).

En el presente siglo el gobierno se ha encargado de las regulaciones sobre el comercio electrónico. Previamente, en 1999 se creó un Grupo para Promover la Legislación del Comercio Electrónico (GILCE), el cual estaba integrado por diversas instituciones, entre ellas: la Asociación de Banqueros de México, la Asociación Nacional de Notarios, la Comisión Federal de Telecomunicaciones, el Banco de México, la Secretaría de Hacienda y Crédito Público, la Secretaría de Economía, mediante la Dirección General de Comercio y Promoción Industrial, la cual se encargó de hacer iniciativas de reformas para el comercio electrónico, orientándose a las siguientes regulaciones: Código Civil, Código de Comercio, Código Federal de Procedimientos Civiles y la Ley Federal de Protección al Consumidor (Palacios, 2003, pp. 75-76). 
A partir del año 2000 el gobierno mexicano se ha enfocado en integrar el uso de las Tic's a la economía, con la finalidad de incrementar su aprovechamiento y fomentar la innovación. Tal como se muestra en la tabla 2, México está llevando a cabo más programas para el desarrollo de las Tic's; sus comienzos fueron en el periodo 2000-2012, cuando se trataba de integrar a la sociedad en el uso de las nuevas tecnologías. En ese periodo se brindaron apoyos gubernamentales para acercar las nuevas tecnologías a la sociedad; en el sexenio 2012-2018 se crearon programas y reformas para fortalecer las TIC's, así como áreas de Internet públicas para que los ciudadanos tuvieran acceso móvil.

Por periodo de gobierno, las siguientes son las estrategias implementadas con el fin de incentivar un mayor uso de las TIC's y por supuesto del comercio electrónico, fomentando así el impulso a la economía digital en el país.

\section{Tabla 2}

Programas gubernamentales para las TIC's en México, 2000-2018

\begin{tabular}{|c|c|c|}
\hline Periodo & Programas & Objetivo \\
\hline \multirow[t]{3}{*}{$2000-2006$} & Proyecto e-México. & $\begin{array}{l}\text { Incentivar la inclusión digital en zonas de difícil } \\
\text { acceso. }\end{array}$ \\
\hline & Enciclomedia. & Reducir la brecha digital en la educación. \\
\hline & RH-net. & $\begin{array}{l}\text { Implementar nuevos mecanismos de } \\
\text { organización del Sistema de Servicio } \\
\text { Profesional de Carrera (SPC). }\end{array}$ \\
\hline \multirow[t]{4}{*}{ 2007-2012 } & $\begin{array}{l}\text { Red Nacional de Impulso } \\
\text { a la Banda Ancha (Red } \\
\text { NIBA). }\end{array}$ & $\begin{array}{l}\text { Crear una red para ofrecer servicios de } \\
\text { conectividad a los actores institucionales del } \\
\text { país. }\end{array}$ \\
\hline & $\begin{array}{l}\text { Impulso a Centros } \\
\text { Comunitarios Digitales } \\
\text { (CCD). }\end{array}$ & $\begin{array}{l}\text { Se proporcionó conectividad a 14,566 ccD para } \\
\text { cubrir la falta de acceso a la misma. }\end{array}$ \\
\hline & $\begin{array}{l}\text { Programa Habilidades } \\
\text { Digitales para Todos } \\
\text { (PHDT). }\end{array}$ & $\begin{array}{l}\text { Se incluyó el uso de aulas telemáticas para } \\
\text { integrar el equipamiento de Enciclomedia } \\
\text { con un sistema de administración tanto de } \\
\text { contenidos educativos como de administración } \\
\text { del portal local. }\end{array}$ \\
\hline & Programa CompuApoyo. & $\begin{array}{l}\text { Trabajadores de empresas afiliadas al Instituto } \\
\text { del Fondo Nacional para el Consumo de los } \\
\text { Trabajadores (Infonacot) recibieron apoyos } \\
\text { gubernamentales para adquirir equipos de } \\
\text { cómputo. }\end{array}$ \\
\hline
\end{tabular}




\begin{tabular}{l|l|l}
\hline Periodo & Programas & Objetivo \\
\hline 2013-2018 & $\begin{array}{l}\text { Reforma en materia de } \\
\text { telecomunicaciones. }\end{array}$ & $\begin{array}{l}\text { Fomentar el desarrollo eficiente de los sectores } \\
\text { de telecomunicaciones y de radiodifusión, así } \\
\text { como asegurar condiciones de competencia, } \\
\text { inclusión social digital y transparencia. }\end{array}$ \\
\cline { 2 - 3 } & Ventanilla Única Nacional. & $\begin{array}{l}\text { Buscó la digitalización de un Catálogo nacional } \\
\text { de trámites y servicios (cNTSE) para los } \\
\text { ciudadanos. }\end{array}$ \\
\cline { 2 - 3 } & México Conectado. & $\begin{array}{l}\text { Garantizar el acceso a Internet en sitios } \\
\text { públicos. }\end{array}$ \\
\cline { 2 - 3 } & $\begin{array}{l}\text { Programa de Inclusión } \\
\text { Digital (PID). }\end{array}$ & $\begin{array}{l}\text { Fomentar el desarrollo de las habilidades } \\
\text { digitales en los estudiantes de escuelas } \\
\text { públicas. }\end{array}$ \\
\cline { 2 - 3 } & $\begin{array}{l}\text { Programa para el } \\
\text { Desarrollo de la Industria } \\
\text { de Software (Prosoft) y la } \\
\text { Innovación. }\end{array}$ & $\begin{array}{l}\text { Impulsar la productividad en sectores } \\
\text { estratégicos del país a través de la adopción de } \\
\text { las Tic's y la innovación. }\end{array}$ \\
\cline { 2 - 3 } Red Compartida. & $\begin{array}{l}\text { Disminuir costos y aumentar la cobertura en } \\
\text { regiones que carecen de servicios de Internet. }\end{array}$ \\
\hline
\end{tabular}

Fuente: elaboración propia con información de AMIPCI (2017b, pp. 6-7).

De esa manera, y como un avance relevante en las transacciones que se realizan a través del comercio electrónico, el 30 de septiembre de 2019 entró en vigor la iniciativa del Banco de México (Banxico) sobre cobros digitales (CoDi), cuya finalidad es facilitar las transacciones electrónicas mediante aplicaciones en los celulares, siendo ésta una nueva forma de pagar y cobrar sin el uso de dinero en efectivo, haciendo las transferencias más rápidas y seguras, así como sin costos adicionales y sin tantas filas para pagos, incentivando de esa manera tanto a los ciudadanos como a las empresas para hacer mayor uso del dinero digital (Banco de México [Banxico], 2020, p. 1).

Todas las estrategias anteriores, además de apoyar a las TIC's también incentivan el uso del comercio electrónico; entre más familiarizados estén los ciudadanos con las tecnologías, mayor será su uso para la adquisición de bienes, servicios o información a través de redes informáticas, es decir, hacer uso del comercio electrónico en los términos en los que se definió anteriormente por Turban et al, (2008, p. 4). 


\section{Conclusiones}

El comercio electrónico es un fenómeno económico relativamente nuevo, propio del siglo XXI y de la economía digital, que impacta a la economía global y de los países, que está transformando la forma de realizar transacciones económicas, en general. En la actualidad no existe prácticamente país alguno que esté fuera de este fenómeno, que está cambiando de forma vertiginosa la forma del intercambio económico.

Aunque sus antecedentes datan de la segunda mitad del siglo xx, fue hacia el último quinto de ese siglo cuando las economías se volvieron más digitales por el uso de las TIC's, provocando con ello una transformación en la sociedad y una mayor adaptación al uso de Internet, lo cual se puede ver reflejado en el creciente uso del comercio electrónico, mismo que no sólo cambió la forma en que se realizaban las transacciones, sino también los hábitos de la sociedad, ya que para muchos es más cómodo realizar las transacciones por medio de Internet, que desplazarse largas distancias a los lugares físicos donde se encuentran las empresas.

Dentro de estos hábitos, se encuentra la forma de interactuar y de facilitar los intercambios y transacciones tanto en el mundo de los negocios como en el accionar del gobierno y de la población en general, para estar ad hoc con el avance de la incorporación cada vez mayor del mundo de las TIC's, expresados de manera clara en las búsquedas y compras más sencillas en el caso de los consumidores, hasta plataformas gubernamentales y de las empresas, para facilitar los trámites y servicios vía electrónica.

Dependiendo del interés de los gobiernos, empresas y consumidores por utilizar las TIC's para el intercambio y comercio electrónico, será la inserción de los países en la era de la economía digital. Obviamente, el costo de oportunidad es muy alto para aquellos países que aún no están incorporados en dicha economía, cuyo rasgo visible es el comercio electrónico.

En China, gobierno, empresas y consumidores están convencidos de los beneficios del comercio electrónico, por lo que promueven acciones para incrementar el uso de las TIC's. Ello explica que el número de usuarios de Internet haya crecido a un ritmo sorprendente, al igual que el comercio electrónico, incrementando con ello la participación de las empresas en las ventas en línea (B2B), que es la modalidad imperante en este país, por los montos que compran las empresas. La aceptación del comercio electrónico en este país ha hecho posible su expansión, lo que se consolida con varias tendencias paralelas: la 
popularidad que han ganado los móviles en las transacciones electrónicas, la utilización de redes sociales como WeChat y la importancia del comercio electrónico transfronterizo.

Asimismo, el gobierno chino ha implementado diversos programas y regulaciones en materia de comercio electrónico, siendo la más actual la creación de la Ley de Comercio Electrónico de 2018, cuyo objetivo es impulsar el crecimiento, mantener el orden y proteger al consumidor de Internet, para brindarle mayor seguridad y certeza en las compras on line.

En México ha aumentado el número de usuarios de Internet y la participación de éstos en las transacciones electrónicas se ha llevado a cabo mediante varias estrategias, entre ellas: premios al comercio electrónico, reconociendo el esfuerzo de las empresas en sus transacciones en línea; campañas como Hot Sale, Hot Monday ocasionales y el Buen Fin, hacia finales de año. También es importante mencionar al gobierno, quien ha llevado a cabo varios proyectos para impulsar el uso de las TIC's desde el año 2000 hasta años recientes, buscando con ello fomentar, apoyar y acercar el uso de las tecnologías a la sociedad.

Por otra parte, no obstante los grandes avances que ha habido en la introducción y uso del comercio electrónico en el mundo y en los casos de China y México, ambas economías requieren fortalecer sus estrategias en comercio electrónico para hacer posible que el comercio electrónico poco a poco se vaya imponiendo como la principal modalidad de consumo en la población. Para ello, deberán seguir fortaleciendo la normatividad e infraestructura computacional y física de seguridad, pues ésta ha sido de los principales obstáculos al momento de realizar transacciones electrónicas. Igualmente importante es impulsar acciones, proyectos y programas que fomenten el uso de las tecnologías, que informen a la sociedad sobre los beneficios de éstas e impulsen el desarrollo del comercio electrónico en definitiva.

Como todo proceso aún en marcha, las vicisitudes que enfrenta en ambos países están conteniendo su potencial. Si bien, como se dijo al inicio de este apartado, hay grandes avances, aún no está del todo desarrollado. Cuando ello llegara a confirmarse, realmente el comercio electrónico estaría siendo parte de un cambio de paradigma en la interacción entre los diversos agentes económicos que intervienen en él, y su contribución al crecimiento y desarrollo económico en el mundo sería un hecho consustancial al desarrollo de la propia sociedad global.

Por último, China aventaja a México en el comercio electrónico, debido a que tanto la sociedad como los agentes económicos han visto e impulsado 
su uso, dados los beneficios concretos que éste tiene. En México, aunque se han realizado acciones a favor del mayor uso del comercio electrónico, aún no se alcanza a percibir su real importancia y ello impide e inhibe su mayor uso y desarrollo. México requiere evaluar las acciones y programas que ha implementado para el impulso del comercio electrónico, pues se puede decir que su potencial aún está en estado latente.

Se termina este artículo, el cual es parte de un proyecto de largo alcance, destacando el hecho de que se dio respuesta a las preguntas que lo estructuraron y que la hipótesis y objetivos de investigación se demostraron con los argumentos, información y datos analizados. Y que las conclusiones dan pie a profundizar en el tema en diversas aristas, como el impacto sectorial e industrial, la innovación en los sistemas de pagos y la demostración de las bondades de las modalidades del comercio electrónico sobre el tradicional o físico.

\section{Referencias}

Aguirre, A., \& Manasía, N. (2007). El comercio electrónico y su aporte socioeducativo. Frónesis, 14(1), 32-50. Recuperado de https://produccioncientificaluz.org/index.php/fronesis/article/view/2997

Asociación Mexicana de Internet (AMIPCI). (2017a). E-commerce Study in Mexico 2017. Recuperado de https://irp-cdn.multiscreensite.com/81280eda/ files/uploaded/Ecommerce\%20Study\%202017.pdf

Asociación Mexicana de Internet (AMIPCI). (2017b). Estudio de inversiones gubernamentales en Tecnologías de la Información y de la Comunicación. Recuperado de https://www.asociaciondeinternet.mx/es/component/ remository/Inversiones-Gubernamentales-en-TICs/Resumen-EjecutivoInversiones-Gubernamentales-en-TICs/lang,es-es/?Itemid=

Asociación Mexicana de Internet (AMIPCI). (2019). Estudio sobre Comercio Electrónico en México 2019: Décima tercera entrega. Recuperado de https:// www.asociaciondeinternet.mx/es/component/remository/ComercioElectronico/Estudio-de-Comercio-Electronico-en-Mexico-2019/lang,eses/?Itemid=

Asociación Mexicana de Venta Online (AMVO). (2018). Libro blanco de logística en el e-Commerce. Recuperado de https://docs.wixstatic.com/ugd/5e9e8f _26179567da124c50a3cda79202c26464.pdf 
Bali, V. 2018. This is what you need to know about China's e-commerce explosion. World Economic Forum. Recuperado de https://www.weforum.org/ agenda/2018/01/china-ecommerce-what-we-can-learn/

Basantes, A., Gallegos, M., Guevara, C., Jácome, A., Posso, A., Quiña, J., \& Vaca, C. (2016). Comercio electrónico. Ibarra, Ecuador: Universidad Técnica del Norte.

Banco de México (Banxico). (2020). Información sobre CoDi® Cobro Digital. Recuperado de https://www.banxico.org.mx/sistemas-de-pago/codicobro-digital-banco-me.html

Cázares, I., \& López, R. (2013). El comercio electrónico en las empresas de Querétaro. CIENCIA@UAQRO, 5(2), 1-12. Recuperado de http://www. uaq.mx/investigacion/revista_ciencia@uaq/ArchivosPDF/v5-n3/art4.pdf China Internet Network Information Center (CNNIC). (January 2018). The $41^{\text {st }}$ Statistical Report on Internet Development in China. Recuperado de https://cnnic.com.cn/IDR/ReportDownloads/201807/ P020180711391069195909.pdf

China Internet Network Information Center (CNNIC). (August 2019). The $44^{\text {th }}$ Statistical Report on Internet Development in China. Recuperado de http://cnnic.com.cn/IDR/ReportDownloads/201911/ P020191112539794960687.pdf

Couture, V., Faber, B., Gu, Y., \& Liu, L. (2017). E-Commerce Integration and Economic Development: Evidence from China (Society for Economic Dynamics, Meeting Papers 114).

Ecommerce Institute. (2019). Ganadores del eCommerce Awards México 2019. Disponible en: http://ecommerceaward.org/mexico/

Fernández-Portillo, A., Sánchez-Escobedo, M., Hernández-Mogollón, R., \& Jiménez-Naranjo, H. (2015). La importancia de la Innovación en el Comercio Electrónico. Universia Business Review, 47, 106-125. Recuperado de https://journals.ucjc.edu/ubr/article/view/1528

González, Y., \& Rodríguez, A. (2008). El mundo y sus contradicciones. Desarrollo vs. Subdesarrollo. Presentado en la IV Conferencia Internacional La obra de Carlos Marx y los desafíos del siglo XXI (pp.1-4), La Habana, Cuba. Recuperado de https://www.nodo50.org/cubasigloXXI/congreso08/ conf4_gonzalezr.pdf

Gutiérrez, E. (2015). Impacto del comercio electrónico en las grandes y medianas empresas de la ciudad de Sogamoso Boyacá, Colombia. Cuadernos 
Latinoamericanos de Administración, 11(20), 83-96. doi: https://doi. org/10.18270/cuaderlam.v11i20.630

Hongfei, Y. (2017). National Report on E-Commerce Development in China (Inclusive and Sustainable Industrial Development Working Paper Series, UNIDO, WP17/2017). Recuperado de https://www.unido.org/sites/ default/files/2017-10/WP_17_2017.pdf

Information Office of the Ministry of Commerce. 2017. 13th Five-year Development Plan for E-commerce Issued by Three Departments.

Instituto Nacional de Estadística, Geografía e Informática (INEGI). (2020). Comercio Electrónico. Recuperado de https://www.inegi.org.mx/temas/ vabcoel/

Li, A. (2017). E-commerce y Taobao Villages: A Promise for China's Rural Development? China Perspectives, 2017/3, 57-62. doi: https://doi.org/10.4000/ chinaperspectives. 7423

Lira, A. (2005). La tecnología de la información y la comunicación: estudio económico. Problemas del desarrollo, 36(143), 189-212. doi: http://dx.doi. org/10.22201/iiec.20078951e.2005.143.7602

Meng, Q., \& Li, M. (2002). New Economy and ICT development in China. Information Economics and Policy, 14(2), 275-295. doi: https://doi.org/10.1016/ S0167-6245(01)00070-1

Mochón, F. (2014). Economía Digital: Una nueva visión para el comercio. Curso MOoc, México: Alfaomega.

National Bureau of Statistics of China (NBSC). (2020). Statistical data: Annual data. Recuperado de http://www.stats.gov.cn/english/Statisticaldata/ AnnualData/

Nielsen. (2016). Dinero Móvil: Cómo la movilidad está transformando el comercio alrededor del mundo de las compras al banco hasta los pagos. Recuperado de https://www.nielsen.com/wp-content/uploads/sites/3/2019/05/EstudioGlobal_DineroM\%C3\%B3vil.pdf

Organización Mundial del Comercio [OMC], y Organización para la Cooperación y el Desarrollo Económicos [OCDE]. (2017). La ayuda para el comercio en sintesis 2017: fomentar el comercio, la inclusión y la conectividad en favor del desarrollo sostenible. París. Disponible en https://www.wto.org/spanish/ res_s/booksp_s/aid4trade17_poket_s.pdf

Organización para la Cooperación y el Desarrollo Económicos (OCDE). (2000). E-commerce: Impacts and policy challenges Outlook. En OCDE, Economic 
Outlook 67 (pp. 193-213). Recuperado de http://www.oecd.org/eco/ outlook/2087433.pdf

Organización Mundial del Comercio (OMC). (2020). Glosario de términos: Comercio electrónico. Recuperado de https://www.wto.org/spanish/ thewto_s/glossary_s/glossary_s.htm

Ordóñez, D. (2003). Sistema Nacional e-México: el nuevo rol del estado de la economía. Revista del Centro de Investigación, 5(20), 57-66. doi: https:// doi.org/10.26457/recein.v5i20.313

Palacios, J. (2003). The Development of E-Commerce in Mexico: a Businessled Passing Boom or a Step Toward the Emergence of a Digital Economy? The Information Society, 19(1), 69-79.

Portillo, J. (2018). ¿Cuáles son las mayores economías del mundo? World Economic Forum. Recuperado de https://es.weforum.org/agenda/2018/10/ cuales-son-las-mayores-economias-del-mundo/

Quintanilla, G. (2003). El uso de las nuevas tecnologías en México. Una sociedad mejor informada. En Memoria del 1er. Congreso Nacional Cultura de la Legalidad e Informática Jurídica, México, Secretaría de Gobernación/ Dirección General de Compilación y Consulta del Orden Jurídico Nacional. Recuperado de http://ordenjuridico.gob.mx/Congreso/pdf/127.pdf Rihui, O., \& Hongxia, M. (2018). Charting the Path of Digital Economy in China. China Today. Recuperado de http://www.chinatoday.com.cn/ ctenglish/2018/tpxw/201812/t20181207_800150937.html

Ríos, A. (2014). Análisis y perspectivas del comercio electrónico en México. Enl@ce Revista Venezolana de Información, Tecnología y Conocimiento, 11(3): 97-121.

Rodríguez, G. (2003). El E-Commerce a nivel internacional: Algunos casos. Revista de Derecho, 20, 12-29.

Sánchez, J., \& Arroyo-Cañada, F. (2016). Diferencias de la adopción del comercio electrónico entre países. Suma de Negocios, 7(16), 141-150. doi: https://doi.org/10.1016/j.sumneg.2016.02.008

Tan, F.B., Scott, P., \& Wong, Y. (1999). Information Technology Diffusion in the Asia Pacific: Perspectives on Policy, Electronic Commerce and Education. London: IGP.

Turban, E., Lee, J., King, D., McKay, J., \& Marshall, P. (2008). Electronic commerce 2008: A Managerial Perspective, (5 ${ }^{\mathrm{a}}$ ed.). New Jersey: Pearson Education. 
United Nations Conference on Trade and Development (UNCTAD). (2001). Informe Sobre Comercio Electrónico y Desarrollo 2001: Tendencias y Resumen Ejecutivo. Recuperado de https://unctad.org/es/docs/ecdr01ove.sp.pdf United Nations Conference on Trade and Development (UNCTAD). (2019a). Digital Economy Report 2019: Value creation and capture: implications for developing countries. Recuperado de https://unctad.org/en/PublicationsLibrary/der2019_en.pdf

United Nations Conference on Trade and Development (UNCTAD). (2019b). E-commerce Week 2019.Recuperado de https://unctad.org/meetings/en/ SessionalDocuments/dtl_eWeek2019_summary_en.pdf

United Nations Conference on Trade and Development (UNCTAD). (2019c). El valor y el papel de los datos en el comercio electrónico y la economía digital y sus implicaciones para el comercio y el desarrollo inclusivos. Recuperado de https://unctad.org/meetings/es/SessionalDocuments/tdb_ede3d2_es.pdf United Nations Conference on Trade and Development (UNCTAD). (2019d). Global e-commerce sales surged to $\$ 29$ trillion. Recuperado de https:// unctad.org/en/pages/newsdetails.aspx?OriginalVersionID=2034

United Nations Conference on Trade and Development (UNCTAD). (2019e). Rapid eTrade Readiness Assessment of Least Developed Countries (eT Ready). Recuperado de https://unctad.org/en/Pages/Publications/E-TradeReadiness-Assessment.aspx

United Nations Conference on Trade and Development (UNCTAD). (2020). Data Protection and Privacy Legislation Worldwide. Recuperado de http:// unctad.org/en/Pages/DTL/STI_and_ICTs/ICT4D-Legislation/eComData-Protection-Laws.aspx

Vega, V. (2016). El comercio electrónico en el marco de la economía actual. Revista de Estudios Económicos y Empresariales, (28): 217-238. Recuperado de http://dehesa.unex.es/handle/10662/6004

Wang, Y., Wang, Y., \& Lee, S. (2017). The Effect of Cross-Border E-Commerce on China's International Trade: An Empirical Study Based on Transaction Cost Analysis. Sustainability, 9 (11), 1-13. doi: https://doi.org/10.3390/ su9112028

Xiang, J., \& Jing L. (2014). Electronic Commerce in China: Current Status, Development Strategies, and New Trends. China Finance and Economic Review, 3, 71-94. 
Xinhua. (2017a). Draft e-commerce law highlights safe trade, consumer rights. Xinhua News. Recuperado de http://www.chinadaily.com.cn/business/2017-11/01/content_33974004.htm

Xinhua. (2017b). El uso del móvil "para todo" en China impacta a un investigador mexicano [Especial]. Xinhua News. Recuperado de http://spanish. xinhuanet.com/2017-04/26/c_136237399.htm

Xinhua. (2018a). Enfoque de China: Innovación, la clave para el desarrollo de China.Xinhua News. Recuperado de http://spanish.xinhuanet.com/201802/27/c_137003441.htm

Xinhua. (2018b). Prospera comercio electrónico en zonas rurales chinas en 2017. Xinhua News. Recuperado de http://spanish.xinhuanet.com/201801/26/c_136926285.htm

Yi, L. (2017). National Report on E-Commerce Development in China (Inclusive and Sustainable Industrial Development Working Paper Series, UNIDO, WP16/2017). Recuperado de https://www.unido.org/sites/default/ files/2017-10/WP_16_2017.pdf

Zhong, Y. (2012). Social Commerce: A New Electronic Commerce. Eleventh Wuhan International Conference on e-Business (pp. 163-169).

Zwass, V. (1996). Electronic Commerce: Structures and Issues. International Journal of Electronic Commerce, 1(1), 3-23. Recuperado de https://www. ijec-web.org/past-issues/volume-1-number-1-fall-1996/ijecv1n1p3-2/ 